The BDJ News section accepts items that include general news, latest research and diary events that interest our readers. Press releases or articles may be edited, and should include a colour photograph if possible. Please direct your correspondence to the News Editor, Arveen Bajaj at the BDJ,

64 Wimpole Street WIG 8YS or by e-mail to bdj@bda-dentistry.org.uk

\section{0th abstract appearance}

This issue marks the 1000th abstract by Dr Trevor Watts, BDJ Adviser on abstracts. Since his first abstract piece in 1989 he has covered a wide variety of topics in clinical dentistry and his 1000th piece (page 607) focuses on necrotizing fasciitis caused by dental infection.

$B D J$ readership surveys consistently show this page to be a popular item in the journal.

Currently, Trevor heads the largest department of periodontology in the UK, a part of Guy's, King's and St Thomas' (GKT) Dental Institute. Before starting his teaching career in 1973 at Manchester, he rose to the rank of Major in the RADC, serving in Britain and Germany.

Over 30 years of teaching, he has developed and enhanced undergraduate and postgraduate education in dentistry and periodontics. He also helped to run the first complete UK specialist training programme in periodontics at Guy's Hospital and has also performed original educational research.

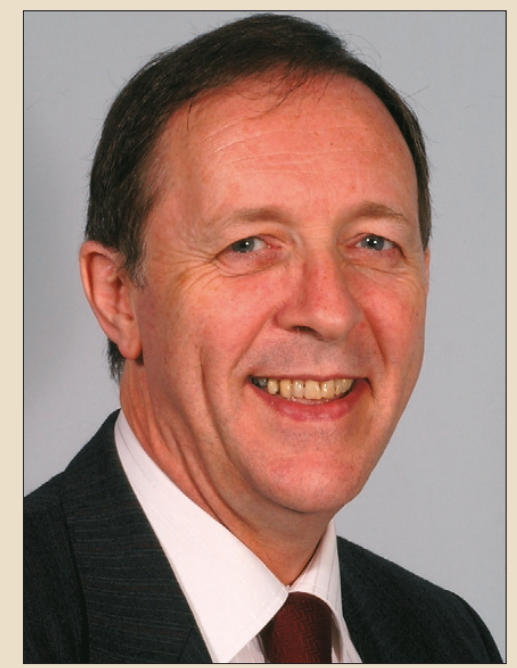

Dr Trevor Watts BDJ Adviser on abstracts

\title{
BSGDS Scholarship awarded
}

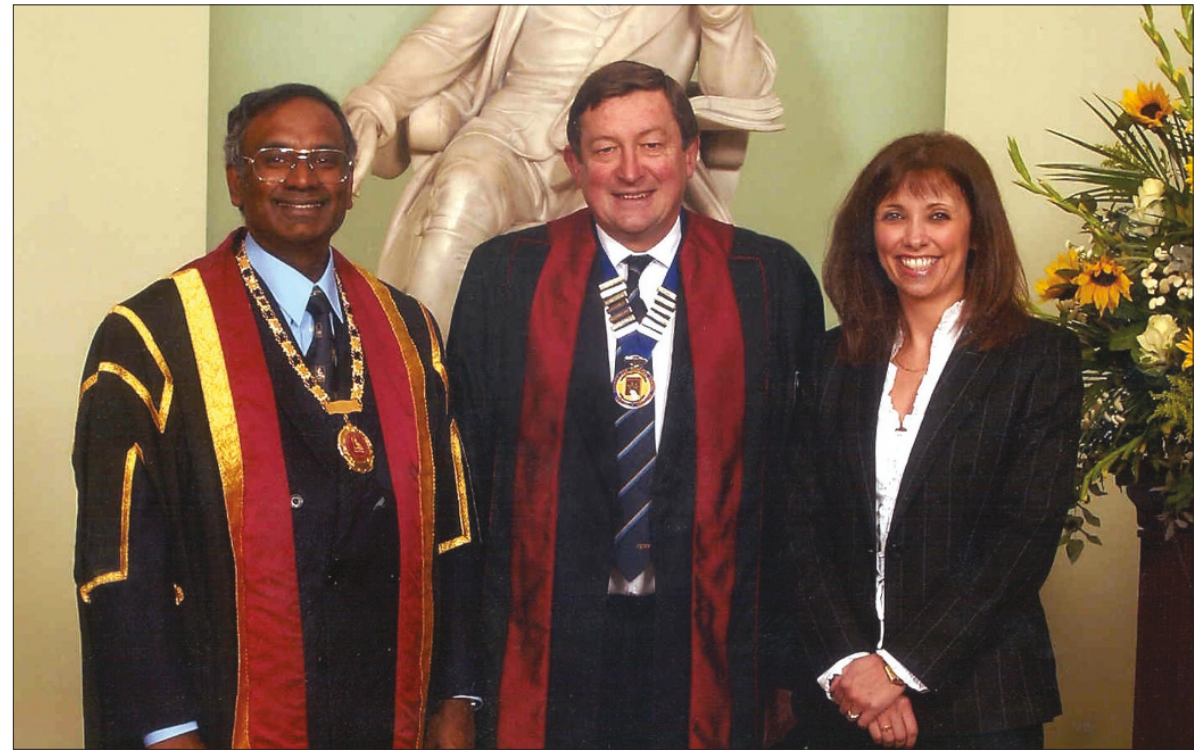

Dr Elaine Downie, (above right) a general dental practitioner from Edinburgh has been awarded the BSGDS Scholarship Award for 2002 by the Faculty of General Dental Practitioners (UK). The scholarship is awarded for research in general dental practice and is sponsored by the British Society for General Dental Surgery. The scholar is chosen after the presentation of a full protocol supporting the idea of research for which training courses have been given at The Royal College of Surgeons of England in London. This assists GDPs in preparing and presenting a formal protocol for research. The winning study will be looking at 'The effectiveness of plantain as a dry socket healer' and the scholar has two years to complete the research and report. The award was presented at the Faculty's Diplomat's ceremony on 1 March where a prize of $€ 2,000$ was awarded to support the research programme.

\section{Curricula framework for PCDs agreed}

The General Dental Council has agreed curricula frameworks for each of the seven PCD groups at its most recent meeting. In its document Developing the dental team: curricula frameworks for registrable qualifications for professionals complementary to dentistry, the GDC sets out curricula requirements for qualifications which will lead to GDC registration for each of the seven groups of PCDs. These include dental hygienists, dental therapists, dental nurses and orthodontic therapists

The GDC claims that the document will enable institutions to start work on developing educational programmes for PCDs and will help it to draft ethical guidance which will underpin GDC reg- istration. Entry to the PCD register will be on the basis of training and qualifications recognised and regulated by the GDC. PCDs who do not have recognised qualifications will be able to register on the basis of their experience for a period of two years from the opening of the register.

Dental nurses with four years' full time experience in the last eight years (or the part time equivalent) and dental technicians with seven years' full time experience in the last ten years (or the part time equivalent) will be eligible. However after the end of the period PCDs will not be able to join the register based on experience alone and will need the 'approved qualification'. 


\section{Charity run reaps rewards}

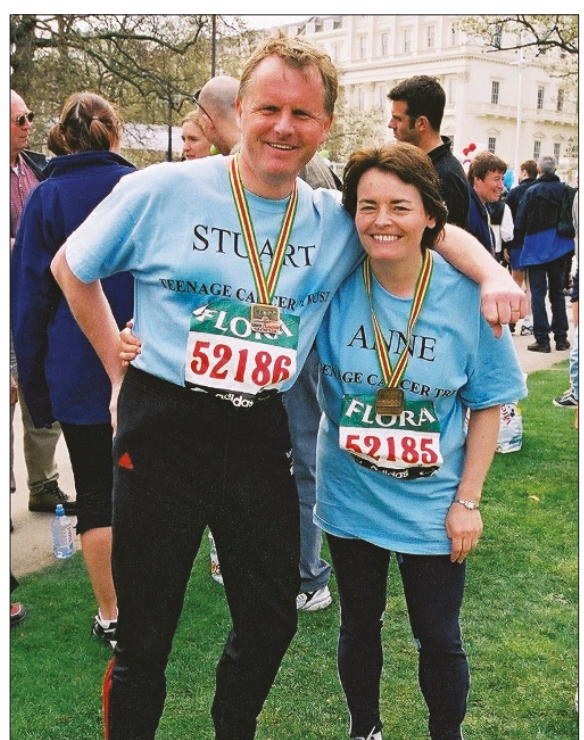

GDP Anne Milarvie and her solicitor husband Stuart Frith both from Leeds, raised $£ 18,000$ for the Teenage Cancer Trust by running the marathon this year.

\section{Winners all round}

This year's dental awards which took place in May saw Martin Anderson of Wessington Way Dental Practice in Sunderland win the dentist of the year award. Kevin Oates from IDH High Street Dental Care won dental hygienist of the year, while Kate Carr of Oasis 611 Dental Care won practice manager of the year.

The judges found choosing an overall team of the year so difficult that they awarded Whitemoss Dental Practice and Service Dental Laboratory as joint winners. They were impressed with the teams' attitude towards staff and patients.

\section{Innovative medical designs from award winning students}

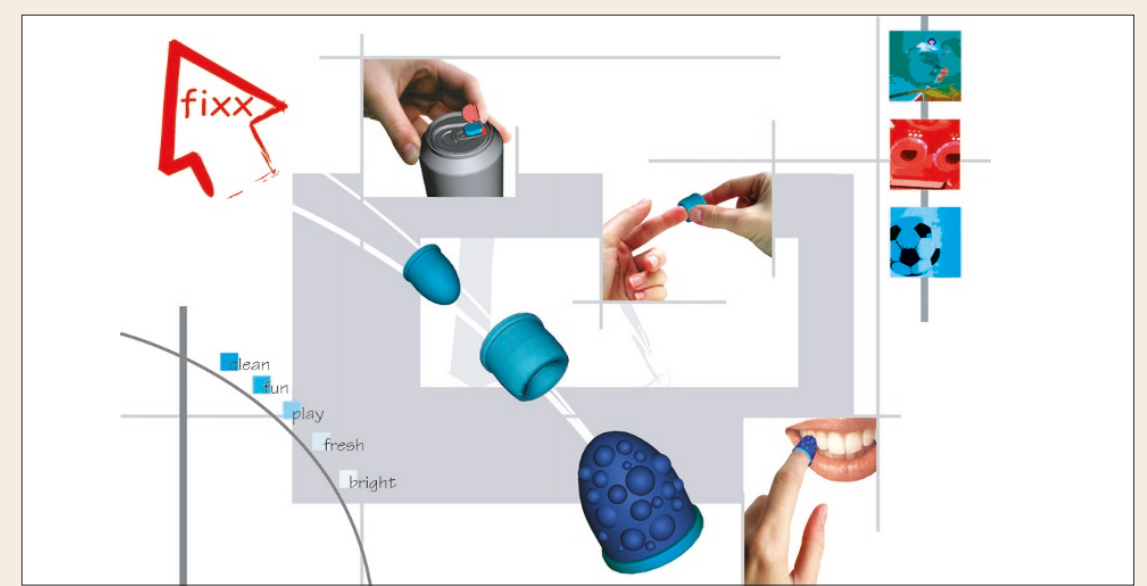

Three award winning young designers have come up with a way of encouraging people to look after their teeth in the medical products category of this year's RSA Student Design Awards.

The students were given the opportunity to improve the daily lives of millions of people around the world by designing an oral healthcare device to encourage the young to buy into the long-term commitment of dental care. Gemma Pridmore of Loughborough University won the GlaxoSmithKline Attachment Award of $£ 3,750$ for her design entitled Fixx (pictured above).

It is aimed at seven to eleven yearolds and tackles the effects of fizzy drink on children's teeth. Designed to secure onto the ring pull of a standard drink with a plastic clip, Fixx is released by peeling back a tamper evident sticker. The bright coloured thimble like device is worn on the finger and rubbed over the teeth. It has a textured outer layer of mint flavoured gum, impregnated with antibacterial agents.

Other winners were Kate Miller of Ravensbourne College of Design and Communication who won the GSK Attachment Award for her design The Fourth Course, a piece of cutlery that sits alongside conventional cutlery consisting of a toothpick mirror and toothbrush.

Gina Reimann, also from Ravensbourne College won the Edward Doherty et Sons Ltd Travel Award of £1,000 for her design, Pen. Aimed at those with a penchant for pen-chewing, the pen is fitted with a mint flavoured nylon chew containing fluoride which helps to prevent tooth decay.

The designs can be seen at the RSAs website at www.rsa-design.net. 


\section{liP status awarded in Bradford}

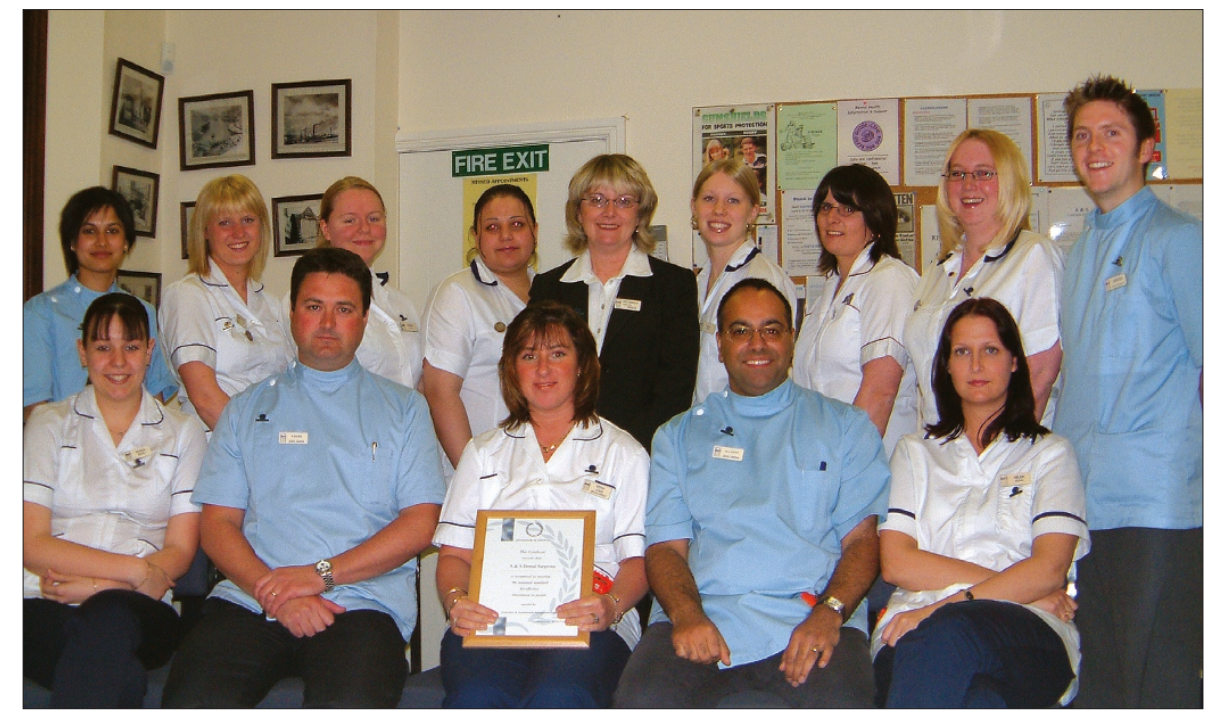

ACtS Dental Surgeons have become the first dental practice in Bradford to achieve Investors in People (liP) status. Originally converted into a dental practice at the inception of the NHS in 1948, it is currently owned by Nick Shore (front row second from left) and Ali Azfar (front row second from right) and is now a large modern six surgery practice committed to the NHS. liP accreditation was awarded to the practice in April.

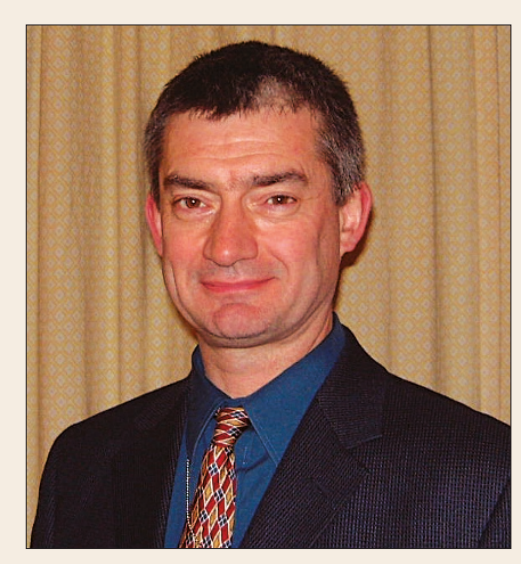

\section{Excellence in teaching}

Teacher Jeff Wilson has been promoted from lecturer to senior lecturer in restorative dentistry in the Department of Adult Dental Health at Cardiff Dental School, University of Wales College of Medicine.

Promoted on the basis of excellence in teaching, he has been a member of the Institute for Learning and Teaching in Higher Education from its inception in 1999 and is also the Dental School's nominated primary contact for the Learning and Teaching Support Network.

\section{Pilot scheme launched to combat tooth decay in school children}

A one month pilot scheme aimed at improving the dental health of local youngsters has begun in Darlington Borough Council. Concerned by the high degree of tooth decay in school children, the local authority has introduced natural mineral water into schools in the area.

A new cartoon character, Dennis Drinkwater (pictured) designed by mineral water supplier Northumbrian Spring will help spearhead the campaign and help get the healthy water message across to local children. Schools taking part include Springfield Primary School, Heathfield Nursery School and Branksome Comprehensive School.

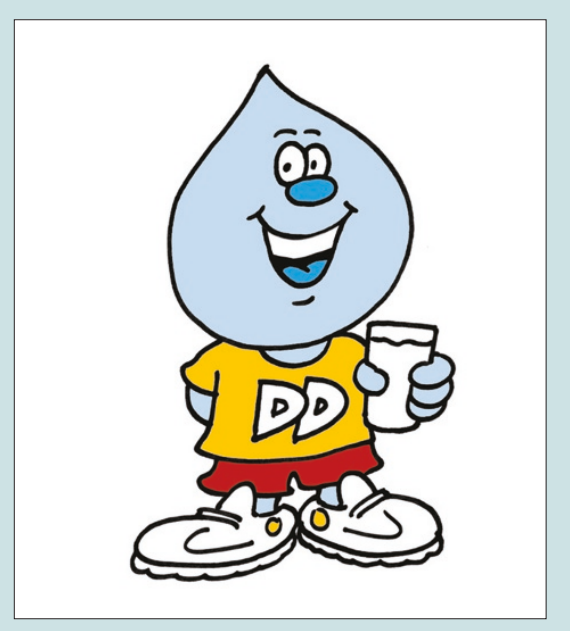




\section{DIARY}

July 2003

17 th Annual meeting of the European Society of Dental Ergonomics

Date: 4-5.07.03

Venue: Rhein-Mosel-Halle, Koblenz, Germany

Contact: Frank Micholt

Tel: +32-2-3 473376

Fax: + 32-11-27 4490

E-mail: secretary.esde@skynet.be

September 2003

Annual Meeting of the International Society for the Prevention of Tobacco Induced Diseases

Date: 29.09.03-01.10.03

Venue: Winnipeg, Canada

Contact: PTID-Society (Congress 2003)

Fax: +1 (204) 789-3913

E-mail: PTIDSociety@AOL.COM

The Faculty of General Dental Practitioners (UK) - Preservative Dentistry: Is less more?

Date: 25.09.03

Venue: Manchester Dental Education

Centre, Manchester

Tel: 01612756600

www.den.man.ac.uk

Young Dentist Conference - Scotland

Date: 13.09 .03

Venue: Hilton Dunblane Hydro

Dunblane

Contact: Julie Fearn

Tel: 01738441040

Fax: 01738441042

E-mail: j.fearn@bda-dentistry.org.uk

\section{October 2003}

9th Biennial Congress of the International

Academy of Periodontology

Date: 24.10.03-27.10.03

Venue: Cape Town International

Conference Centre

Tel: +27219389245

Fax: +27 219332649

www.sun.ac.za/iap2003

\section{May 2004}

BDA National Annual Conference

Date: 06.05.04 - 08-05.04

Contact: Events Office,

British Dental Association

Venue: Bouremouth International Centre

Tel: +44 (0) 2075634590

Fax: +44 (0) 2075634591

E-mail: events@bda.org

\section{Success for Welsh nurses}

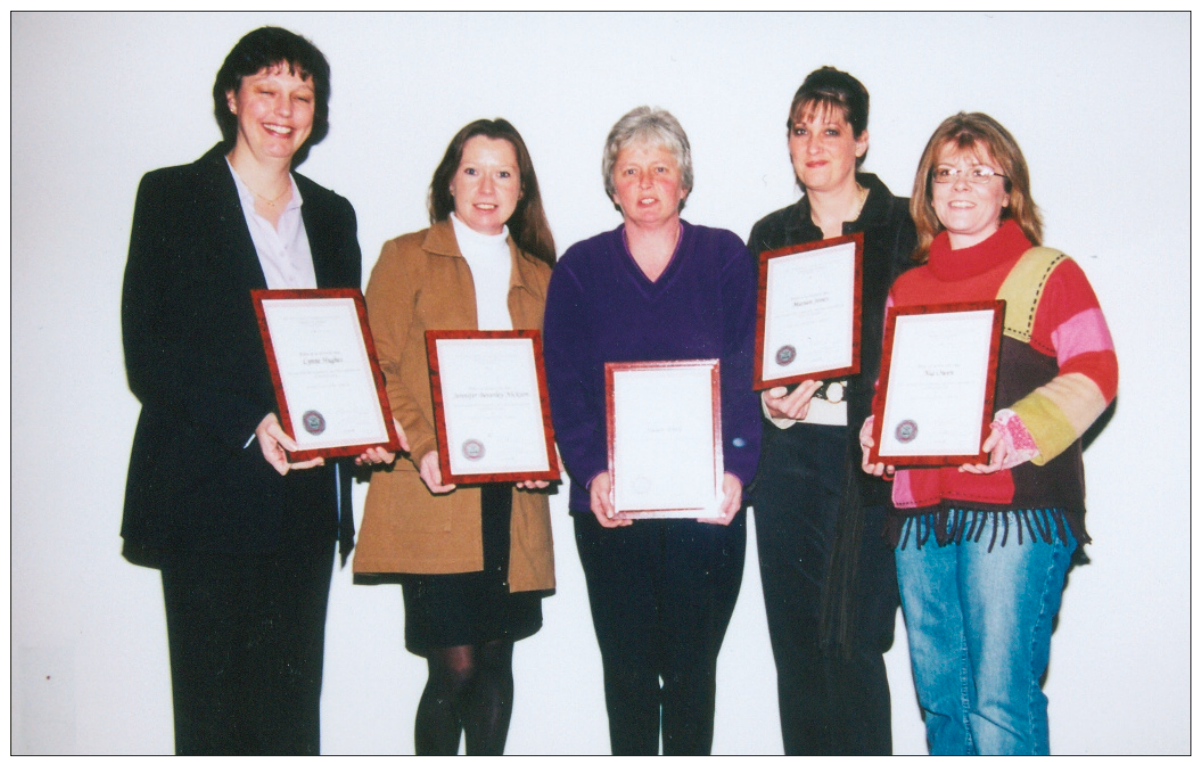

Dental nurses Lynne Hughes, Jenny Nixon, Sue Jones, Amanda Harris and Nia Owen (from left to right) from North Wales have successfully completed the first Special Care Dental Nurses course to be held in Wales. The course commenced in September 2001 and the next course is due to begin in September 2003.

\section{SARS thwarts charity trek}

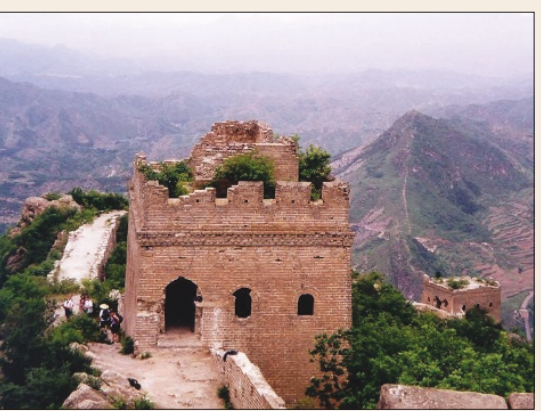

The outbreak of SARS in China has halted dental charity Dentaid's endeavours to hold a fund-raising trek along the Great Wall of China in August this year.

The 27 participants who had signed up for the eight day trip have been advised that it will be moved to August 2004 instead.

The postponement has been a major blow to the charity as it is the second time that a fundraising event has had to be moved. The charity's Grand Canyon Cycle Challenge organised by Practice Plan was originally scheduled for September 2001 but was stopped due to the September 11 terrorist attack. It did however take place the following summer and was a huge success, raising $£ 40,000$.

Ironically, Dentaid picked China as the venue for the sponsored event as it was considered to be one of the more

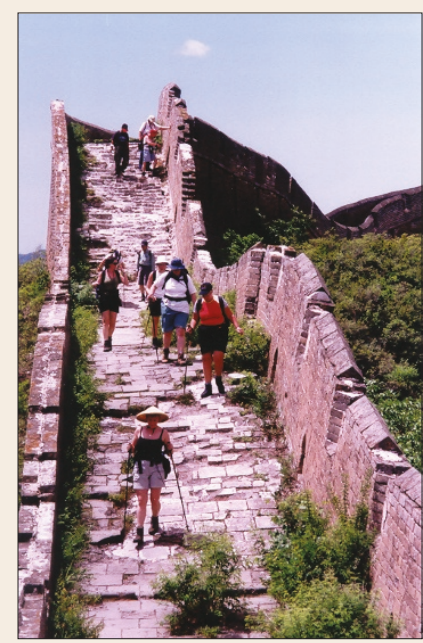

politically stable destinations, taking into consideration recent world events.

The charity concentrates on collecting dental equipment donated by UK dentists and refurbishes it to send it to areas of great need worldwide. Details about the trek are available from jenny@dentaid.org or telephone 01794 324249.

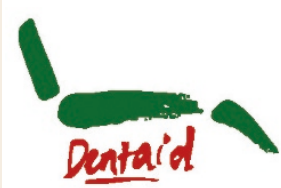

